\title{
CONTRAPONTO AO REDUCIONISMO “GRAFITE VERSUS PICHAÇÃo” em São Paulo, CAPITAl
}

\author{
Marcos Zibordi \\ Escola de Comunicações e Artes, Universidade de São Paulo, Brasil
}

\begin{abstract}
RESUMO
Pretende-se problematizar a propalada divisão entre grafites e pichações em São Paulo, capital, maior cidade brasileira, onde existiriam duas manifestações visuais diferentes, com praticantes exclusivos, sendo o grafite sempre colorido, autorizado pelo dono do suporte e positivo para a paisagem, enquanto à pichação caberia poluir a cidade com letras pretas, crípticas e indecifráveis, atitude criminalizável. Pretendemos demonstrar, ao contrário, confluências de processos de modelização poética em "imagens isoladas", "sequências" e "quadros" de grafites e pichações em todas as regiões da capital paulista. Após uma primeira etnografia em busca dessas imagens em diferentes períodos entre 2011 e 2015, para a pesquisa de doutoramento, captamos registros fotográficos inéditos em setembro de 2019, aos quais relacionaremos a base teórica semiótica e estrutural (Lotman, 1978; Todorov, 1969, 1971, 1980) e o referencial da epistemologia complexa (Morin, 2013, 2008).
\end{abstract}

\author{
Palavras-chave
}

grafite; graffiti; pichação; pixação; São Paulo

\section{COUNTERPOINT TO “GRAFFITI VERSUS PICHAÇÃo” Reductionism in SÃo PAulo, CAPITAl}

\begin{abstract}
It is intended to problematize the propagated division between graffiti styles in São Paulo, capital, the largest Brazilian city, where there would be two different visual manifestations, with exclusive practitioners, with the graphite always colored, authorized by the owner of the support and positive for the landscape, while graffiti would have to pollute the city with black, cryptic and indecipherable letters, a criminalizable attitude. On the contrary, we intend to demonstrate the confluences of poetic modeling processes in "isolated images", "sequences" and "pictures" in all regions of the São Paulo capital. After the first ethnography in search of these images in different periods between 2011 and 2015, for doctoral research, we captured unpublished photographic records in September 2019, to which we will relate the semiotic and structural theoretical basis (Lotman, 1978; Todorov, 1969, 1971, 1980) and the reference of complex epistemology (Morin, 2013, 2008).
\end{abstract}

\section{KEYWORDS}

graphite; graffiti; pichação; pixação; São Paulo 


\section{INTRODUÇÃO INTEGRADORA}

Na capital do maior estado brasileiro, São Paulo, a propalada divisão entre o "grafite" e a "pichação", também grafada com "x", estigmatiza os registros nos muros, no alto dos prédios e viadutos como palavras presumivelmente indecifráveis, registradas em uma só cor, sobretudo o preto, formando conjuntos clandestinos e criminalizados; de outro lado estariam os grafites, admiráveis pela contribuição colorida ao cinza da cidade, miríade de imagens autorizadas por donos de muros e outras fachadas, tendencialmente ao nível da rua.'

Essa divisão, que parece natural (Casseano, Domenich \& Rocha, 2001; Fideles, 2014; Gitahy, 1999; Malland, 2012, entre outros), redesenha, precisamente, a segunda proposta metodológica cartesiana anunciada há 380 anos em $O$ discurso do método: - pesquisador deveria "dividir cada uma das dificuldades que examinasse em tantas parcelas quanto fosse possível e necessário para melhor resolvê-las" (Descartes, 2001, p. 23). Em abordagem mais complexa, na linha de Edgar Morin, estaríamos diante do "paradigma da simplificação" que opera destruindo "os conjuntos e as totalidades" e isolando "todos os objetos daquilo que os envolve" (Morin, 2008, p. 18).

Apesar da representatividade da produção visual da capital paulista, dividida em dois tipos de manifestações visuais que seriam não só diferentes, mas opostas, predomina a incompreensão. As idiossincrasias classificatórias começam com a defesa preciosista do termo grafitti, plural de grafitto em italiano (Gitahy, 1999). Na mesma linha de ordem ortográfica, cobra-se o uso do "x" em "pixação", para acentuar a postura antinormativa.

Não separar aquilo que seria "o" grafite, em geral figurativo, das produções tipológicas e outros presumíveis estilos, sobretudo aqueles ontem e hoje chamados de pichação, ao contrário do consenso paulistano, divisionista, respeita a trajetória histórica desses registros visuais que, em São Paulo, foram inspirados pela produção dos Estados Unidos, tido como berço da cultura hip hop, da qual as imagens são parte, ou elementos, incluindo a música (rap), o trabalho dos DJs e a dança.

O histórico documentário Style Wars (Silver, 1983), sobre o grafite em Nova lorque, mostra que a maioria dos jovens pintava letras e figuras, com recorrente inspiração em histórias em quadrinhos e super-heróis. Eram os writers, escritores, em sua maioria autores de tipologias coloridas ou monocromáticas muito semelhantes ao que chamamos atualmente de pichação em São Paulo, onde prevalece um ponto de vista separatista compartilhado por teóricos, mídia e senso comum, apesar das evidências históricas e empíricas relativas à produção grafiteira, que nunca deixou de incluir estilos tipológicos, figurativos ou mistos.

Tratando do mesmo contexto do documentário mencionado acima, na Nova lorque do início da década de 1970 Baudrillard compreende frases e desenhos indistintamente

\footnotetext{
' Versão inicial apresentada no I Simpósio Internacional de Comunicação e Cultura, realizado em São Caetano do Sul (SP), em 2015, durante pesquisa de doutorado na Escola de Comunicações e Artes (ECA) da Universidade de São Paulo (USP). Esta versão incorpora sugestões de avaliadores e debatedores do referido Simpósio e dos integrantes da banca de doutoramento, em 2016, além de imagens atualizadas e inéditas, captadas para este artigo em 2019.
} 
como grafites, um "tipo novo de intervenção na cidade" (1996, p. 100). A metrópole segregadora adquiria outras dimensões além da predominância da atividade econômica, tornando-se prioritariamente "o lugar de execução do signo" (1996, p. 100), socializando imagens pelo tecido urbano.

Grafitar em Nova lorque era tão malvisto quanto pichar em São Paulo no terceiro milênio, mas a cisão diferenciadora é um preciosismo paulistano que, devido à influência da capital sobre o país, da economia à cultura, espalhou o paradigma reducionista. Concordamos com Baudrillard (1996) quando afirma que as imagens nos muros não são organizadas como mensagens publicitárias ou políticas, facilmente identificáveis e classificáveis, normatizadoras e excludentes. A cidade é um palco de semioses, um "polígono dos signos" caótico para "violentas insurreições visuais" (Baudrillard, 1996, p. 101).

Para o teórico, as imagens em trens, postes e outros suportes públicos "têm uma verdadeira carga simbólica" (Baudrillard, 1996, p. 102), codificando e recodificando os espaços, incidindo sobretudo na arquitetura. Rebeldes visuais demarcam com imagens seu "verdadeiro terreno estratégico, o da manipulação dos códigos e das significações" (Baudrillard, 1996, p. 104), embaralhando os signos tradicionais - a função poética das imagens seria criar novos modelos de percepção visual.

Entre os autores que encaram esses registos de forma orgânica, considerando o imbricamento, e não a divisão entre grafites e pichações, encontramos teóricos da França, Inglaterra, Estados Unidos, Colômbia e, em menor quantidade, brasileiros. Apesar de diferentes nacionalidades e objetos de análise, eles tendem a tratar a pichação como sinônimo de grafite ou encaram o grafite como um conjunto de manifestações visuais, incluindo a pichação, às vezes até mais valorizada (Art, Manco \& Neelon, 2005; Boleta, 2006; Chastanet, 2007; Ferreira, 2006; Franco, 2009; Ganz, 2010; Lassala, 2010; Silva, 2014). Nas imagens públicas paulistanas, desde o final da década de 1970 as produções incorporam desenhos de letras e figuras, tornadas, portariormente, patrimônios e territórios exclusivos, respectivamente, do grafite e da pichação (Fonseca, 1981).

Consideramos que ocorrem afinidades, ainda mais quando partimos de "um ponto fundamental da reflexão" que relaciona grafites e pichações: a "comunhão subterrânea que possuem, tanto na história das práticas, como nas interdependências processuais para interferirem na cidade" (Franco, 2009, p. 20). Para outro autor, "os grafiteiros, em sua maioria, consideram a pixação como uma, senão a mais autêntica, forma de graffiti, denominando as letras dos pixadores como tag reto. Inclusive em outros países o graffiti engloba ambas as formas de manifestação" (Ferreira, 2006, p. 37).

Tomando as imagens paulistanas em acepção semiótica, procuraremos caracterizar três conjuntos visuais recorrentes em São Paulo, considerando a estruturação poética, que os distingue, e a expressividade lírica, que lhes é comum. Esses conjuntos "imagens isoladas", "sequências" e "quadros" - serão vistos como "textos".

Os textos que servem como material primário para pesquisa, podem ser distinguidos de acordo com a substância dos signos que os constituem. Em particular, podem funcionar como substância o discurso escrito ou oral, 
sequências de representações gráficas, pictóricas ou plásticas, complexos arquitetônicos, frases vocais ou musicais, gestos, certas formas típicas de comportamento humano (por exemplo, o estado de sono, de hipnose, de êxtase, etc.) e formas de comportamento notadamente comuns (por exemplo, comer), bem como objetos de uso cotidiano incorporados na esfera do culto. Quanto à substância, um texto pode ser homogêneo (por exemplo, o texto escrito do Alcorão) ou heterogêneo, ou seja, constituído pela combinação dos elementos indicados (por exemplo, canto religioso $=$ discurso oral + melodia; pintura mural dos templos = discurso escrito + representações pictográficas + elementos do complexo arquitetônico; o serviço religioso, que em seus exemplos mais completos reúne quase todos os elementos acima enumerados). (Ivanov, Toporóv \& Zalizniak, 1979, p. 81)

Apoiados nesse marco teórico, ao tratarmos de "imagens" estaremos nos referindo a textos visuais isolados ou a conjuntos compostos pelo que normalmente se distingue como grafites e pichações, ou seja, propomos uma abordagem englobante desses textos visuais estruturados a partir de "modelizações" (Lotman, 1978, p. 35).

Considerando Lotman (1978), as "imagens isoladas", "sequências" e "quadros" resultam de "modelizações secundárias" porque baseadas em outros sistemas semióticos, como cores e palavras, em desenhos figurativos ou psicodélicos, escritos críticos ou espirituosos, marcas visuais específicas de grupos e artistas. Os limites físicos dessas modelizações são dados pela espacialidade dos suportes, como muros e fachadas. Segundo Baudrillard, ainda que "selvagens, coletivos, anônimos, eles respeitam seu suporte e a linguagem pictorial, mesmo que para articular um ato político" (1996, p. 106).

A complexidade das modelizações é proporcional à quantidade de informação veiculada publicamente pelas imagens, tendo em vista que "a complexificação do caráter da informação arrasta inevitavelmente a complexificação do sistema semiótico utilizado para a transmitir" (Lotman, 1978, p. 38). Por ocorrerem em ambiente social, as modelizações mobilizam signos internos e externos, sem os quais "a obra em geral não poderia ser portadora de qualquer significação" (Lotman, 1978, p. 101).

Da nossa perspectiva, dois mecanismos opostos atuam na construção da cultura visual paulistana: a pretendida predominância positiva dos grafites tenta "submeter todos os elementos do texto ao sistema, e transformá-lo numa gramática automatizada, sem a qual o ato de comunicação é impossível", enquanto a pichação tenderia a "destruir essa automatização e a fazer da própria estrutura o portador da informação" (Lotman, 1978, p. 137).

Esse jogo constitutivo implica muito mais interdependência e correlação do que diferenças, por isso discordamos da separação corrente e propomos outra delimitação, do ponto de vista da estruturação poética e da intenção lírica, ainda apoiados na noção semiótica de "fronteira". Ela demarca o limite de determinada estrutura, como o quadro, o palco, o tempo da música ou o fim de um muro. Paradigmas artísticos geram fronteiras, que podem ser pessoais, autorais, ideológicas e, obviamente, físicas, como 
fachadas e postes. "O modo como o texto é dividido pela sua fronteira constitui uma de suas características essenciais" (Lotman, 1978, p. 373).

A noção de fronteira é dinâmica, permitindo a compreensão da diversidade, da individualidade e da relação entre textos culturais modelizados e modelizantes, agindo como um mecanismo de limitação e permeabilidade. Ao tratar do duplo aspecto das fronteiras, que pressupõem demarcação e porosidade, Edgar Morin afirma que

embora tenhamos a tendência a considerar as fronteiras essencialmente como linhas de exclusão, a palavra fronteira, aqui, revela a unidade da dupla identidade, que é ao mesmo tempo distinção e pertencimento. A fronteira é ao mesmo tempo abertura e fechamento. É na fronteira que ocorrem a distinção e a ligação com o ambiente. Toda fronteira, inclusive a membrana dos seres vivos, inclusive a fronteira das nações, é barreira e, ao mesmo tempo, o local da comunicação e da troca. É o lugar da dissociação e da associação, da separação e da articulação. Ela é o filtro que ao mesmo tempo obstrui e deixa passar. É através dela que se estabelecem as correntes osmóticas e é ela que impede a homogeneização. (Morin, 2013, p. 252)

\section{Procedimentos}

Quanto à metodologia deste artigo, nossa proposta integradora resulta da observação e registro de imagens chamadas de grafites e pichações em todas as regiões da capital paulista, em diferentes períodos entre 2011 e 2015, além de etnografia realizada em setembro de 2019, para atualização do material de campo.

Fomos a praças, becos, ruas, avenidas e rodovias. Para chegar até elas, utilizou-se, sobretudo, bicicleta, além de trens e metrôs paulistanos, que aos finais de semana, dia preferencial para os registros das imagens, permitem levar bicicletas nos vagões. $\mathrm{Na}$ maioria das vezes, chegamos a lugares centrais e periféricos com transporte público para, então, explorar regiões específicas pedalando.

O equipamento utilizado, máquina fotográfica e celular (este, exclusivamente na atualização de 2019), produziu fotografias e pequenos vídeos. Na capital paulista, a escolha dos dias e horários aos sábados, domingos e feriados evita o movimento intenso de carros e pessoas diante dos textos visuais, com a vantagem de que é possível observar imagens nas fachadas desdobráveis de metal, especialmente as portas de comércios. Em 12 incursões etnográficas entre 2011 e 2015, coligimos 3.556 fotos e 287 vídeos, apresentados junto à tese de doutorado. Em 2019, realizamos 120 fotos e 17 vídeos de curta duração para este artigo.

As limitações da fotografia, que em muitos casos não abarca a dimensão da imagem a ser registrada, conflui para importante desdobramento teórico: a dificuldade em fotografar conjuntos maiores, geralmente horizontais, obrigou a filmá-los, e então percebemos que o encadeamento construído raramente estabelece elos lógicos entre as partes, pois são somatórias quase sempre aleatórias. 
A princípio, captamos imagens em grandes vias, que seriam preferidas pelos autores pela visibilidade. Porém, para enxergar a situação em locais menos movimentados, realizamos, no trabalho etnográfico, mapeamento específico na zona oeste da capital paulista, nos arreadores da Universidade de São Paulo (USP), onde percebemos que a intensidade e proporção das imagens é praticamente a mesma, independentemente do tamanho das vias.

O mais relevante resultado, conforme estamos insistindo, é a percepção de que predomina a convivência entre os chamados grafites e pichações na estruturação de textos visuais: os suportes escolhidos são os mesmos; quase sempre os autores praticam ou praticaram as duas tendências; os registros estão em toda a cidade; os artistas utilizam materiais e técnicas similares, como tinta spray e látex espalhada com rolo; e nem sempre se pode distinguir o que seria grafite ou pichação, tal a mistura de estilos e o imbricamento dos registros.

Eles constituem a base empírica para propormos a tríade de textos visuais a seguir, mas tal categorização, evidentemente, não esgota as possibilidades classificatórias das incontáveis imagens encontráveis nos muros, fachadas, paredes, postes, portas, portões, orelhões, colunas, caixas de telefonia e construções, abandonadas ou não, na capital paulista.

\section{ESTRUTURAÇÃo POÉTICA DAS IMAGENS}

As "imagens isoladas", "sequências" e "quadros" pouco correspondem às ordens causais e temporais das narrativas mais comuns. Elas tendem ao atemporal e a fazer das "relações espaciais elementos que constituem a organização" (Todorov, 197ı, p. 61).

Contudo, não se pode anular a marca temporal de nenhuma narrativa, pois mesmo estruturada para parecer prescindir do tempo, ou quando realmente diminui sua importância, o receptor inevitavelmente atribuirá temporalidades, a começar pelo período dispensado a ler.

A tendência à atemporalidade dos textos visuais que incluem grafites e pichações implica em que as relações cronológicas não encadeiam nem desencadeiam sua constituição, e na maior parte das vezes a causalidade entre acontecimentos não determina correlações. Obras organizadas no espaço não são "habitualmente" compreendidas como narrativas, lembra Todorov, para quem as unidades dessas composições terão "disposição mais ou menos regular" e as "distribuições gráficas ou fônicas assumem um valor de símbolo na ordem espacial" (1971, p. 63).

Afirmar que as imagens tendem à atemporalidade não significa que ela seja nula, mas que a estruturação é prioritariamente espacial. Existem questões complexas sobre o tempo que, por não ser o foco da discussão, vão aqui pontuadas, abarcando comentários de arguto comentador deste artigo: as camadas narrativas das imagens de grafites e pichações registradas em diferentes temporalidades - enquanto algumas se apagam, outras são novas - impõem trânsito entre passado e presente, além da própria compactação dos registros, que incitam, ao mesmo tempo, brevidade e permanência. 
Enfim, se a temporalidade é menos decisiva na estruturação de grafites e pichações, podendo assumir papel relevante quando as imagens estão expostas ao público, a espacialidade é determinante nos textos visuais paulistanos, considerando que há enorme diferença entre escrever poesia para provocar imagens mentais (Pound, 1990, p. 63) e utilizar o suporte espacial como elemento estruturante do poético. Os concretistas brasileiros defendiam procedimentos contra a prosa e o prosaísmo apostando no "branco da página como elemento de estrutura" (Pignatari, 1975, p. 63). Para os concretistas e para os chamados grafiteiros e pichadores, a produção poética redimensiona a hierarquia que prioriza a palavra. Outros elementos constituintes, como imagens, cores e o próprio suporte, passam a ter equivalente relevância.

A consciência da relação com o suporte, decisiva porque constituinte, começa com a elaboração e reelaboração exaustiva de rascunhos em folhas guardadas em pastas ou cadernos dos autores, os chamados piecebooks. Neles, busca-se a melhor composição que, de tão treinada, facilita a adaptação a inúmeros espaços e cores disponíveis:

a poesia concreta coloca o poema sob o foco de uma consciência rigorosamente organizadora, que atua sobre o material da poesia da maneira mais ampla e mais consequente possível: palavra, sílaba, fonema, som, fisiognomia acústico-verbal-visual dos elementos linguísticos, campo gráfico como fator de estruturação espaciotemporal (ritmo orgânico), constelações semânticas precipitadas em cadeia e consideradas simplesmente do ponto-de-vista do material, em pé de igualdade com os resultantes elementos de composição. (Campos, 1975, p. 51).

Importante reter da citação a mencionada "consciência rigorosamente organizadora", pois ela identifica procedimento de construção fundamental de textos visuais na capital paulista, que começam nos rascunhos exaustivamente refeitos em cadernos.

Em condições apressadas de registro na rua, e mesmo quando estão fazendo "produções" (trabalho coletivo de grafiteiros em suportes autorizados), os artistas devem desenvolver a capacidade de riscar o suporte com precisão, tecendo sua marca adaptada ao espaço e cores disponíveis, de preferência em uma única tentativa. Há pouquíssima possibilidade de corrigir, menos ainda de apagar a imagem que não saiu a contento. $\mathrm{A}$ cada registro, tipologias e desenhos figurativos são adaptados, relacionados e hierarquizados conforme o suporte, autorizado ou não, e para isso a "consciência rigorosamente organizadora" é indispensável.

\section{IMAGENS ISOLADAS}

As imagens que aparecem sozinhas nos suportes públicos paulistanos não são capazes de engendrar ações e personagens, não têm fôlego para desenvolvimentos narrativos mínimos nos moldes prosaicos, são figuras soltas nos suportes, como as raras (porque temporárias) assinaturas isoladas em muros acabados de pintar, em postes, ou pequenos desenhos em caixas de telefonia, assim como enormes figuras nas laterais de prédios e colunas de viadutos. 
Essas aparições atomizadas estão no polo oposto das histórias cuja relação "dominante" (Jakobson, 1983, p. 485) entre as partes é determinada pela causalidade e "cada unidade encontra seu lugar na narrativa porque houve ou porque há tal outra unidade" (Todorov, 1971, p. 52). Nas imagens isoladas, a carência de meios narrativos impede que elas possam formar trama e, menos ainda, seu resultante inevitável, a intriga, entendida como a passagem de um equilíbrio a outro.

Tome-se como exemplo a expressão específica de grafiteiros e pichadores, o bombing, que nomeia um dos tipos recorrentes de imagem isolada em São Paulo (Art, Manco \& Neeloon, 2005, p. 33; Ganz, 2010, p. 390). O bombing significa e propõe, literalmente, bombardear os suportes, palavra usada tanto para se referir às inscrições nos trens de Nova lorque, nos anos 60 e 70, como para as encontradas em São Paulo, em 2019.

A produção poética estruturada em princípios de atomização ou compactação impactante é muitas vezes inspirada em práticas orientais, como o haicai, de origem japonesa, composição mínima cheia de significados. No Brasil, no século passado, praticaram poemas curtos e curtíssimos autores anteriores ao Modernismo paulista, poetas posteriores e fora desse circuito, como o pernambucano João Cabral de Melo Neto e os chamados concretistas (Aguilar, 2005), com os quais dialogaremos neste artigo, assim como o contemporâneo Paulo Leminski.

Há pelo menos um século registram-se produções de haicais no Brasil e, lembra Leminski, "nos anos 70, por fim, a garotada da poesia marginal ou alternativa, crescida com manchetes de jornal, frases de 'out-door' e grafittis nas paredes das cidades que inchavam, começou a fazer 'haikais', até sem querer" (2001, p. 113).

Usando termos como "niponização" e "miniaturização" para tratar de "poesia breve, sintética, anti-discursiva", Leminski associa a tradição japonesa às poéticas contemporâneas, pois "hai-kai é o nosso tempo, baby. Um tempo compacto, um tempo 'clip', um tempo 'bip', um tempo 'chips'” (2001, p. 101).

Compactar pressupõe trabalho minucioso, como na poda de bonsais, minúsculas árvores orientais cuja criação é associada a processos poéticos como os que modelizam os textos visuais paulistanos. Diante dos suportes públicos, os autores devem manusear com precisão os rolos de tinta, pinceis e, especialmente, as latas de spray, com o qual "você precisa de ar comprimido e de compressão da expressão. Ela tem que ser breve, seja verbal ou não-verbal, ou incluindo ambos" (Fonseca, 1981, p. 36).

Ainda sobre confluentes estruturações poéticas sintetizantes, um poeta referencial para os concretistas brasileiros, Erza Pound, define o procedimento poético como "a mais condensada forma de expressão verbal" (1990, p. 40) e identifica no ideograma chinês o princípio composicional compacto:

os egípcios acabaram por usar figuras abreviadas para representar sons, mas os chineses ainda usam figuras abreviadas "como" figuras, isto é, o ideograma chinês não tenta ser a imagem de um som ou um signo escrito que relembre um som, mas é ainda o desenho de uma coisa; de uma coisa em uma dada posição ou relação, ou de uma combinação de coisas. O 
ideograma significa a coisa, ou a ação ou situação ou qualidade, pertinente às diversas coisas que ele configura. (Pound, 1990, p. 26).

As duas imagens a seguir tendem a ser identificadas como pichação e grafite, mas são igualmente textos visuais atomizados em suportes nos quais sobra espaço para futuras figuras, não necessariamente do mesmo estilo das anteriores.

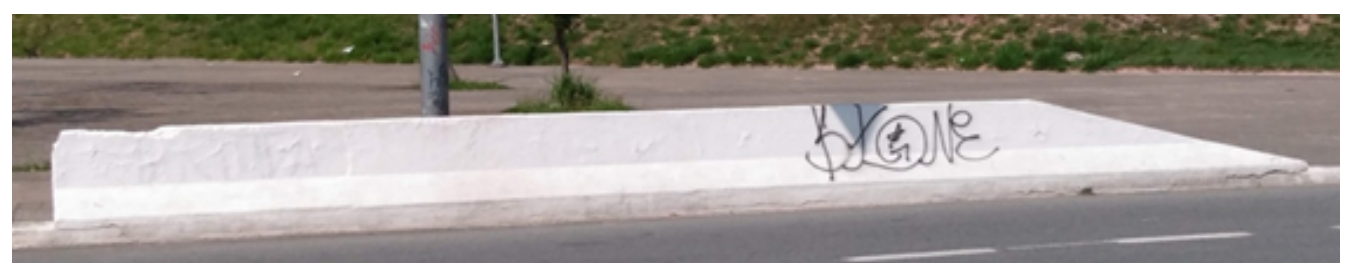

Figura 1: Estação Itaquera, zona leste, 14 de Setembro de 2019

Créditos: Marcos Zibordi

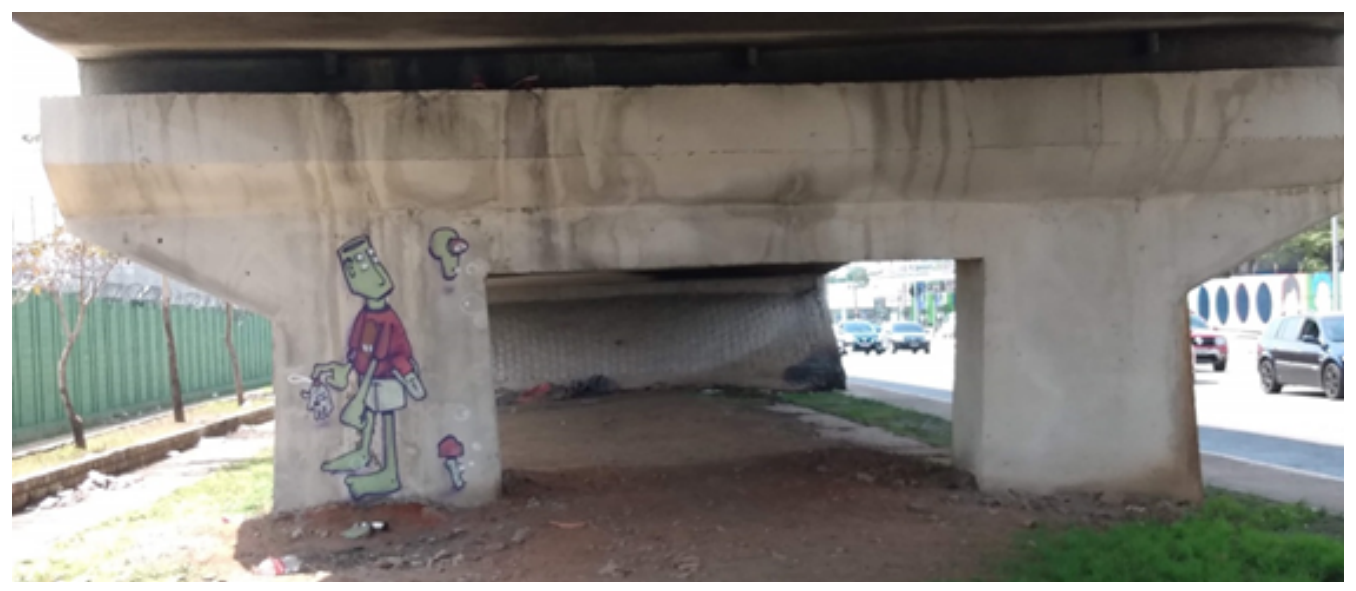

Figura 2: Av. Radial Leste, 14 de Setembro de 2019

Créditos: Marcos Zibordi

Nos dois próximos exemplos, um texto visual pichado ocupa pequeno suporte, a lixeira, imagem comumente identificada como pichação; contudo, enquanto registro único, resulta de processos de modelização similares ao grafite que ocupa a lateral inteira do prédio. 


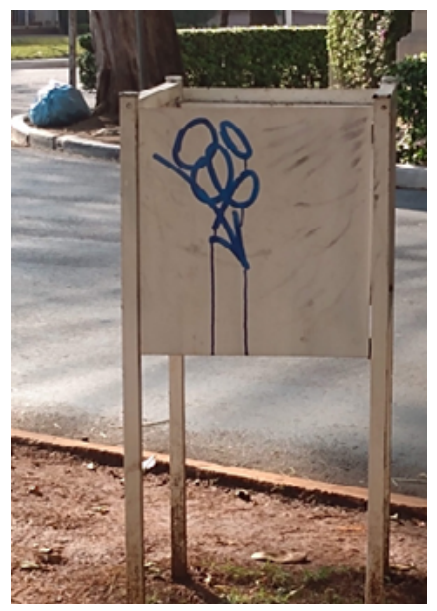

Figura 3: Região central, 14 de Setembro de 2019 Créditos: Marcos Zibordi

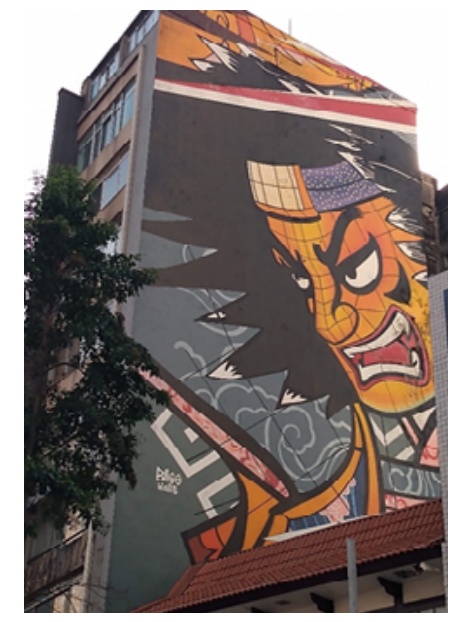

Figura 4: Região central, 14 de Setembro de 2019

Créditos: Marcos Zibordi

Do ponto de vista da modelização poética em relação ao suporte, as presumíveis diferenças de estilos fazem pouca diferença, conforme pretendemos ter demonstrado nas duas situações anteriores: as imagens isoladas podem ocupar toda a área disponível ou sobra espaço para o surgimento de novos registros.

Quando eles aparecem, sobretudo aos lados, a imagem isolada passará a ser parte de uma sequência ou de um quadro, desempenhando, ao longo de sua existência, a dupla função de ser inicialmente atomizada e, em seguida, desencadeadora de processos acumulativos que formam sequências, textos visuais predominantes na capital paulista.

\section{AS SEQUÊNCIAS}

Elas são formadas pelos chamados grafites submetidos à inevitável horizontalidade dos muros, pelas linhas pichadas no topo dos prédios, além de sequências verticais 
em laterais de edifícios, colunas e postes, em três situações: sequências de grafites, de pichações e aquelas nas quais os dois estilos estão misturados - a situação híbrida nos é epistemologicamente cara, pois problematiza a presumível pureza de dois grupos de registros visuais que seriam muito diferentes e separados na capital paulista, conforme contrapõe nossa argumentação principal.

As sequências são estruturadas por figuras ou tipologias, coloridas ou não, com ao menos dois elementos que teriam tudo para constituir, ao menos, frases, orações e até períodos, no caso de palavras, ou séries cartesianamente lógicas de desenhos figurativos, como nas histórias em quadrinhos. Porém, apesar do acúmulo de imagens, os encadeamentos narrativos praticamente não ocorrem.

O principal motivo para considerar conjuntos de imagens como "sequências" é a organização espacial obrigatoriamente horizontal, que ocorre com muito mais frequência, ou vertical, direções sempre dadas pelas condições do suporte. Essas sequências no mínimo duplicam o sentido de leitura com o qual a maioria dos ocidentais se acostuma, sempre da esquerda para a direita. A dupla direção possível de produção e visualização das sequências potencializa as possibilidades do princípio de continuidade típico da prosa, restrita ao sentido único, do começo em direção ao final, por etapas, enquanto nestes textos visuais sequenciais, o início e o fim são intercambiáveis. Além de quebrar a linearidade de sentido único, as sequências aparecem duplicadas quando acima, abaixo ou ao lado de uma linha vertical ou horizontal, surge outra, independente do estilo.

Aristóteles, ao tratar da tragédia, estabelece um pressuposto fundamental relativo ao encadeamento de partes da história: "é muito diverso acontecer uma coisa por causa de outra, ou acontecer meramente depois de outra" (1991, p. 14). A diferença fundamental ocorre entre acumulação e organização sequencial orgânica dos elementos narrativos.

Esse ponto de vista teórico milenar vem reverberando em autores para os quais as sequências, para serem propriamente narrativas, precisam atender a determinadas condições. Segundo Bremond, a "sequência elementar" (2008, p. 115) cumpre três fases obrigatórias, processo que abre e fecha ciclos de acontecimentos ou ações. Ele é claro sobre as relações imperativas entre essas partes no todo narrativo, pois “onde não há integração na unidade de uma ação, não há narrativa, mas somente cronologia, enunciação de uma sucessão de fatos não-coordenados" (Bremond, 2008, p. 118).

É precisamente isso que ocorre nas sequências de textos visuais tecidas com grafites e pichações na capital paulista: acumuladas todas ao mesmo tempo ou ao longo dos dias, geralmente são encadeadas obedecendo ao princípio de sucessão, menos complexo do ponto de vista das relações de transformação narrativa. Ao invés de ciclos, as imagens são partes, uma ao lado da outra, e "a narrativa não se contenta com isso, exige o desenvolvimento de uma ação, isto é, a mudança, a diferença" (Todorov, 1980, p. 62).

Nesse sentido, mesmo as ações de personagens, grafitadas ou pichadas, teriam, no máximo, "potência evocadora", que "por si mesmas, só muito dificilmente poderiam produzir uma sequência narrativa autônoma" (Todorov, 1980, p. 70). Em geral, os personagens são encadeados, não encaixados, e "encaixe" é processo básico de construção narrativa prosaica porque 
a aparição de uma nova personagem ocasiona infalivelmente a interrupção da história precedente, para que uma nova história, a que explica o 'eu estou aqui agora' da nova personagem, nos seja contada. Uma história segunda é englobada na primeira; esse processo se chama encaixe. (Todorov, 1969, p. 123)

Isso explicita a diferença entre a lógica da consecução nas sequências de textos visuais, baseada na soma e autonomia das partes em relação ao todo narrativo, e a lógica da consequência, necessariamente relacionando, implicando, imbricando ciclos de acontecimentos, ações ou personagens, procedimento de modelização dificilmente visto nas sequências paulistanas.

Sua tessitura acumulativa pouco relacional, estruturada pelas condições e limites da espacialidade, explica porque elas não desenvolvem tema único, quer dizer, não há ideia central perpassando as partes, construindo a temática (Tomachevski, 1976). Apesar da aparente semelhança com procedimentos narrativos da prosa, as sequências não a realizam, pois a acumulação tende ao movimento linear, horizontal e bidirecional, mas não tece sequer o clássico e óbvio começo, meio e fim.

Essas acumulações não são prosaicas sobretudo porque predomina a estruturação poética em outro aspecto da relação entre as partes, através do ritmo. Ele revela a poética dos textos visuais sequenciais no sentido de que as leis da combinação das partes, sejam grafites ou pichações, são também as leis do ritmo (Brik, 1976).

Esse ritmo tende à uniformidade devido aos espaços semelhantes ocupados por cada registro visual na sequência. Quando resultam de "produções", nas quais artistas se juntam para "fazer um muro", dividindo-o em partes iguais na altura e largura, o ritmo é marcadamente regular. $E$ também varia pouco quando são aproveitados os intervalos prévios e proporcionais de suportes cujas partes similares existem, por exemplo, pela divisão de colunas simétricas de um muro ou viaduto.

No sentido atribuído por Lotman, as sequências são "organizações por equivalência" e no "texto poético" (1978, p. 188), estruturado horizontal ou verticalmente nas ruas de São Paulo, "as palavras verificam-se ser equivalentes unicamente em razão do seu isometrismo" (Lotam, 1978, p. 205). Assim, "esta repetição dos segmentos rítmicos cria a presunção de equivalência recíproca de todos os elementos do texto no interior de dados níveis, que constitui o fundamento da percepção do texto como poético" (Lotam, 1978, p. 207).

Sequências de textos visuais públicos paulistanos, sem tema unificante, nem trama, realizam tessitura poética pela predominância do ritmo, com raríssimas sequências formando narrativas, apesar da acumulação e regularidade dos registros, como nas duas modelizações a seguir, raras porque compostas unicamente de pichações (a primeira), e grafites (a segunda). 


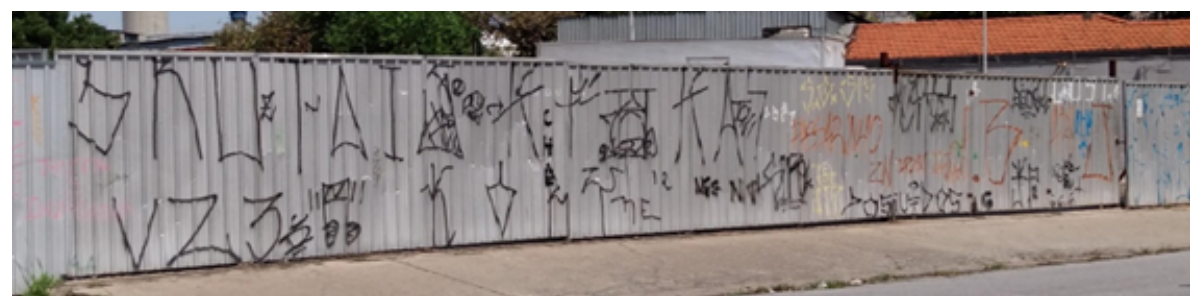

Figura 5: Sequência pichada na zona norte, Praça Orlando Silva, 14 de Setembro de 2019

Créditos: Marcos Zibordi

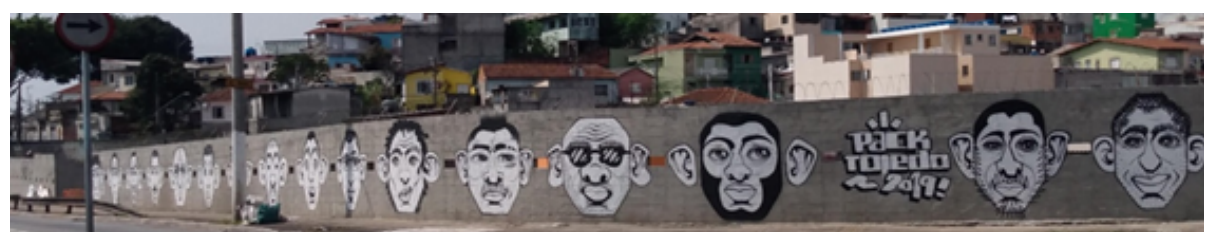

Figura 6: Esquina da Radial Leste, zona leste, regularidade rítmica grafitada, 14 de Setembro de 2019 Créditos: Marcos Zibordi

Contudo, conforme estamos insistindo, nas etnografias constatamos mistura estilística, conforme as próximas imagens evidenciarão. São três sequências com modelizações diferentes: a parede de um viaduto apresenta grafites de um lado e pichações de outro; tipologias das duas tendências são intercaladas regularmente em um tapume de metal; logotipos comerciais, letras e desenhos dos dois estilos formam a fachada de oficina.

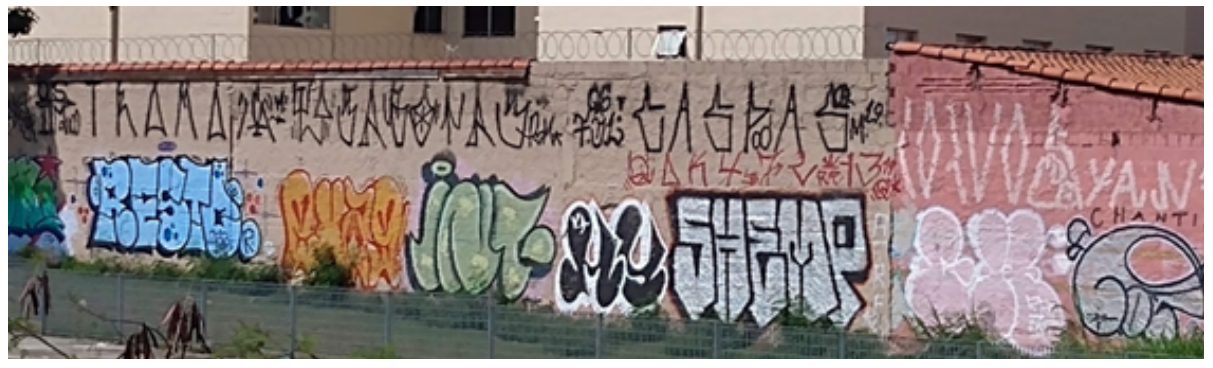

Figura 7: Proximidades Arena Corinthians, zona leste 14 de Setembro de 2019

Créditos: Marcos Zibordi

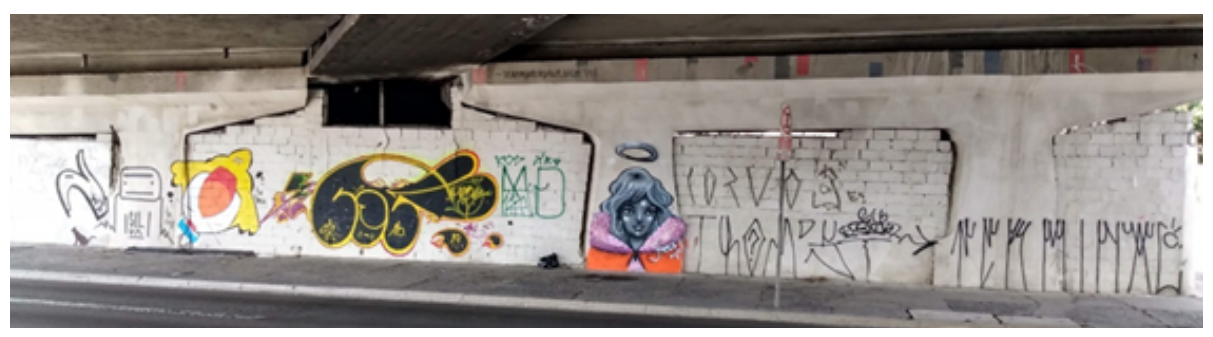

Figura 8: Parte inferior de viaduto próximo à Avenida Consolação, centro, 14 de Setembro de 2019 Créditos: Marcos Zibordi 


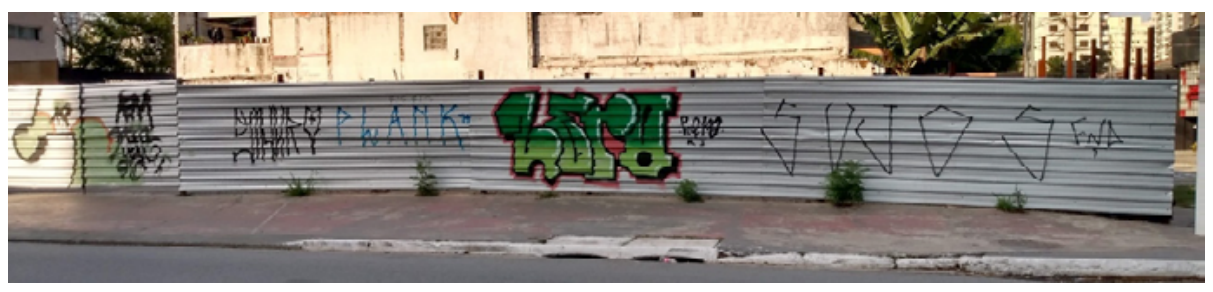

Figura 9: Avenida Cidade Jardim, zona sul, 14 de setembro de 2019

Créditos: Marcos Zibordi

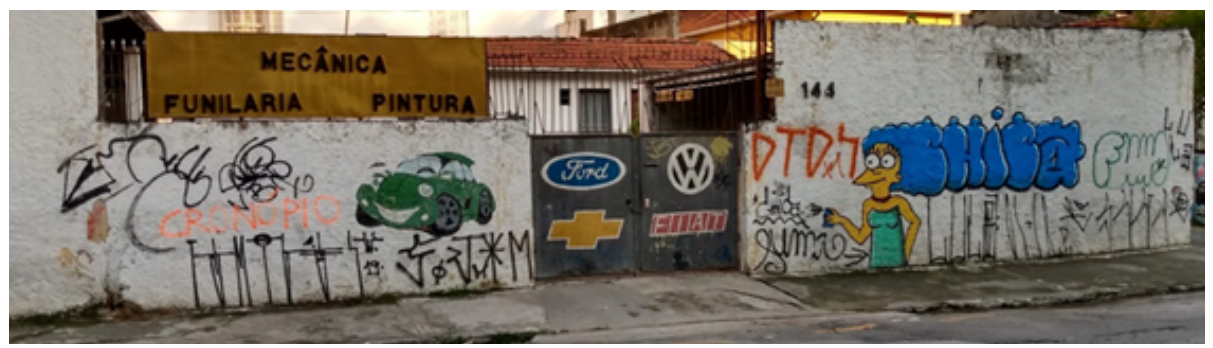

Figura 10: Praça Elis Regina, zona oeste, 14 de Setembro de 2019

Créditos: Marcos Zibordi

Nas imagens, não há conexão causal entre as partes, ocorrem poucos engates narrativos entre os registros visuais. Se, por exemplo, há um morto desenhado, dificilmente alguém fará o assassino atirando, assim como as frases não tendem a ser completadas, questionadas, ironizadas, pervertidas.

Cada texto visual ocupa seu espaço, preferencialmente similar e os autores não abrem mão da egocêntrica autoria ao registrarem suas produções, seus nomes, marcas ou figuras nas paredes. Estão juntos, mas não misturados a ponto de a autonomia das partes contribuir ou ser diluída no todo narrativo - elas permanecem identificáveis, gravitando nas sequências.

\section{OS QUADROS}

Quanto ao terceiro tipo de texto visual composto por imagens que se identificam como grafites e pichações em São Paulo, os "quadros", assim como as imagens isoladas e sequências, pouco realizam tessitura propriamente narrativa, mas o ritmo muda decisivamente, pois nos quadros, bem mais caóticos que as sequências, a formação dos conjuntos de imagens perde em regularidade e ganha em complexidade. Diferentes da acumulação linear em dois sentidos, horizontal e vertical, típica das sequências, os quadros engendram múltiplos ritmos, como os diagonais. Quadros não são necessariamente quadrados, mas tendem a ser quando quebram a predominante horizontalidade das sequências.

A estruturação dos quadros é a menos lógica dos três conjuntos de imagens propostos e a mais próxima de certa organização propriamente poética no sentido de "procedimento associativo, a maior parte abaixo do limiar da consciência" e cuja "unidade 
mais natural" é a "unidade descontínua" promovendo "ligações de sentido ambíguo, e ligações de memória muito semelhantes às do sono" (Frye, 1973, p. 267).

Quadros são enormes paredões eivados de grafites, pichações ou ambos, e nos obrigam a esticar o pescoço nas visualizações para os lados, acima, nas diagonais. Testemunhamos a adrenalina que permeia o processo de registro de alguns textos visuais chamados de pichação: no topo de um prédio do centro da cidade, alguém segura as pernas para outro que, de cabeça para baixo, maneja o rolo de tinta que produz o novo registro (vale mais se for o primeiro), ou mais um no suporte (vale menos, a não ser que seja mais alto) (Boleta, 2006).

Apesar de todas as relações possíveis que modelizam os elementos visuais no suporte, quadros são bastante caóticos, ou complexos, e aqui cabe outra diferenciação em relação às sequências: nestas, a inevitável e estruturante horizontalidade resulta em tessitura acumulativa, menos tecida, mais somada, linear e cartesiana, enquanto quadros promovem linhas de força visuais em diversas direções, imprevisíveis, fazendo da tessitura processo mais orgânico, intrincado e não linear.

Assim, o ritmo irregular das imagens nos quadros tece movimento similar ao das palavras no "verso livre", sem métrica rígida, não admitindo "união com os ritmos habituais dos versos regulares e necessitam de um princípio autônomo de construção" (Tomachevski, 1976, p. 153).

Nos quadros, os elementos visuais são tecidos em procedimento de modelização poética como o proposto pelo poeta dadaísta Tristan Tzara, que experimentou maneiras de questionar a ordem lógica recortando palavras do jornal, embaralhando-as e jogando sobre a mesa, considerando poema a construção resultante. Tal tessitura não é engendrada prioritariamente pelas relações semânticas nem sintáticas racionais, menos ainda pelas regras da língua, sentido, extensão ou sonoridade das palavras. Predomina a "técnica das correspondências, as associações fragmentárias de ideias e as insólitas combinações" (Richter, 1973, p. 60).

Desse modo, somos obrigados a chegar a uma conclusão: a estrutura relacional não é uma soma de pormenores materiais, mas um conjunto de relações que está em primeiro lugar na obra de arte e que constituiu o seu fundamento, a sua realidade. Mas este conjunto constrói-se não como uma hierarquia com vários andares sem intersecções internas, mas como uma estrutura complexa de subestruturas que se intersectam com numerosas penetrações de um único e mesmo elemento em diferentes contextos construtivos. (Lotman, 1978, p. 145)

A seguir, veremos quadros modelizados com variações tipológicas pichadas em parede, seguida de coluna com grafites figurativos e letras, e na terceira composição, tipologias dos dois estilos. 


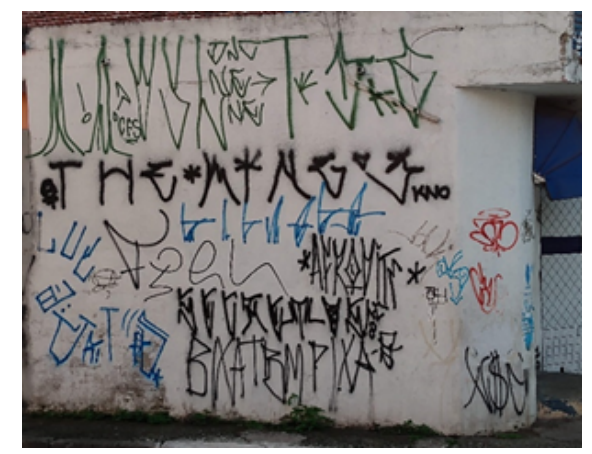

Figura 11: Quadros na Vila Gomes (Oeste), 14 de Setembro de 2019 Créditos: Marcos Zibordi

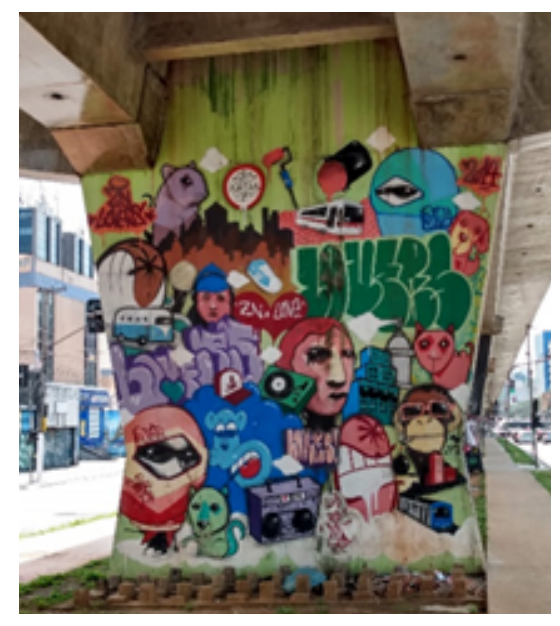

Figura 12: Quadros na Av. Cruzeiro do Sul (Norte), 14 de Setembro de 2019

Créditos: Marcos Zibordi

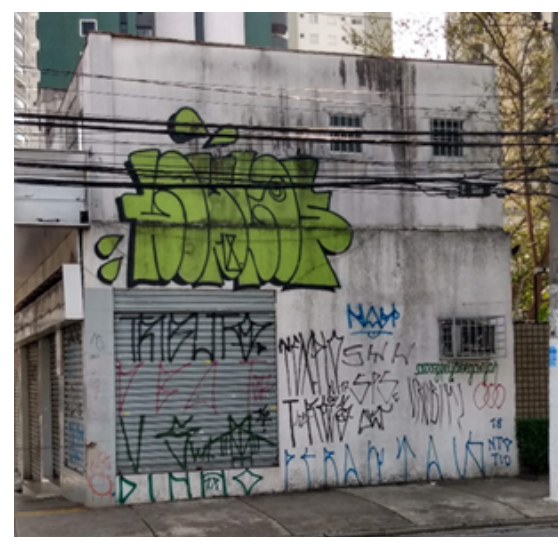

Figura 13: Letras de grafites e pichações, metrô Estação Vila Mariana (Sul), 14 de setembro de 2019

Créditos: Marcos Zibordi

As modelizações poéticas, por mais cerebrais que sejam, não prescindem do lírico. Nos quadros anteriores, o lirismo está na grandiloquência das cores e formas, como também nas enormes dimensões. 
Historicamente, a relação entre poético e lírico é cada vez menos direta. Determinadas vertentes, como as concretistas, pretendem evitar o derramamento lírico, exterminando a "poesia estado-místico" (Campos, 1975, p. 52). O lirismo pode abrolhar da mera catarse, inclusive sem intenção poética, literária ou artística. Entre interações possíveis, estamos afirmando que nos três conjuntos de textos visuais que descrevemos, a estruturação poética é diferente, mas todos expressam lirismo.

Nos termos de Jakobson, imagens "isoladas", "sequências" e "quadros" realizam uma "função emotiva", aquela centrada no remetente visando "uma expressão direta da atitude de quem fala em relação àquilo de que está falando. Tende a suscitar a impressão de uma certa emoção, verdadeira ou simulada" (2007, pp. 122-123).

\section{CONFLUÊNCIAS LÍ́RICAS}

Expressar os próprios sentimentos é sinônimo perene de lírico. Mencionamos, anteriormente, Aristóteles; suas ideias, assim como as de Platão, foram retomadas e sistematizadas por Hegel (Leite, 2005, p. 9). Para o filósofo alemão, o poeta lírico "utiliza a ocasião apenas como oportunidade, a fim de expressar em geral a si mesmo, sua disposição, sua alegria, sua tristeza ou modo de pensar e ponto de vista sobre a vida", centrado na "própria vitalidade autônoma de seus sentimentos e considerações" (Leite, 2005, p. 163).

Na tríade de textos visuais paulistanos, a demarcação da expressão do eu é evidente nos indispensáveis e egocêntricos registros de nomes ou vulgos de autores e grupos, tanto de grafiteiros, quanto de pichadores. Ocorre que o '“interno' e 'externo', 'subjetivo' e 'objetivo' não estão absolutamente diversificados" (Staiger, 1972, p. 58).

Nas "imagens isoladas", "sequências" e "quadros", reina a indistinção: desenhos podem tender ao realismo; existem psicodélicos com traços figurativos; personagens oscilam entre midiáticos, como os de desenhos animados, e autorais, com tendência a rostos e faces masculinas; há frases espirituosas, políticas, nomes de grupos e autores; e no que diz respeito a letras e palavras, são as que mais aproximam o que seriam duas manifestações distintas, ao contrário da divisão comum que associa, genericamente, letras a pichação e desenhos a grafites - o interesse tipológico é comum.

A dominante onírica das imagens também promove lirismo, saltando aos olhos naquelas que evocam o mundo dos sonhos e nas quais a subjetividade é exacerbada pela profusão de cores - exuberância, derramamento e exagero dão o tom em registros escapistas cuja volatilidade constrói textura lírica ainda pela deterioração natural dos suportes, desbastando o impacto inicial das cores aberrantes. Nesse sentido, os muros funcionam como palimpsestos, nome dado a pergaminhos apagados para reutilização.

O sujeito disposto liricamente "se considera uno com esta paisagem, com este sorriso, com este som, portanto, não com o eterno, mas justamente com o mais passageiro" (Staiger, 1972, p. 61). Sobre isso, leiamos um trecho de entrevista com o grafiteiro Tiago Batista dos Santos, o "Calle", ou "rua" em espanhol. Perguntamos se ele costuma contar a quantidade de grafites realizados. Eis sua resposta lírica baseada na ação do tempo sobre as imagens: 
quem faz isso faz, e eu entendo mais ou menos porque, mas eu não tenho porque ficar falando eu fiz duas mil laterais. Eu sei lá mano, eu passei uns anos da minha vida fazendo, só posso falar isso, tá ligado? Não vou ficar contando, tem vários que eu não lembro, tem vários que eu perdi a foto, o barato é desapego, você tem que ser natural truta, você tem que ser natural! Por isso que é bom pintar de látex, porque o látex ele apaga, ele perde muito mais vida rápido, então o grafite ele é apagado mais rápido que a pichação, acredite se quiser. A pichação agride, mas é o grafite que é apagado. Por isso que é bom a gente fazer com látex porque a gente vê o tempo que passou pelo grafite de verdade, você olha a parede, você vê que ela está desgastada e só faz quatro anos. Na gringa os caras pintam só com spray, então a parada é muito mais profissional, dura bem mais, e aqui não, a parada é bem mais natural, é látex, é tinta a base de água, tá entendendo? E aí você vê o tempo passando na rua, assim: é uma mensagem, uma ideia que estava passando pela sua cabeça, que você fez no seu nome, várias pessoas não entendem, mas você quis passar uma mensagem dentro do seu nome, dentro de um estilo, com cores, tudo pensado. Quatro anos e o barato está lá, você passou por ali com aquelas ideias, tá ligado? E aí é o que faz eu amar a parada. (Calle, entrevista pessoal, 20 de julho, 2014)

O lírico, aqui tomado no sentido ocasional, é "arte do precário, uma espécie de manchete lírico-poética" (Fonseca, 1981, p. 59). Não se refere somente ao autor exprimindo suas sensações, mas ao aspecto dominante nas próprias imagens, impactantes pelas enormes dimensões, pela surpresa com que aparecem e somem da cidade, pela procura do espaço mais visível para o registro, para aparecer ao máximo de pessoas e exprimir paixões e desejos, monocromáticos e multicoloridos. As imagens querem nos atingir, sequestrar pela emoção, e quando são indecifráveis racionalmente, mergulhamos em impressões porque "a língua da poesia é uma língua difícil, obscura, cheia de obstáculos" (Chklovski, 1976, p. 55).

Daí se depreende o último aspecto lírico que gostaríamos de destacar: a afronta. Imagens isoladas, sequências e quadros pretendem causar impacto visual: "mais amiúde do que qualquer outro gênero, a lírica depende, em seu efeito principal, da imagem surpreendente ou louçã, fato que muitas vezes dá origem à ilusão de que tal uso das imagens é radicalmente novo ou não convencional" (Frye, 1973, p. 277).

\section{DO QUE SE PODE INFERIR}

A distinção entre grafites e pichações é improdutiva para caracterizar as modelizações poéticas visuais paulistanas, para nós estruturadas em correlação. Retomando a classificação triádica proposta, sustentamos que nas imagens isoladas a noção de unidade identificável modeliza o poético; nas sequências, a linearidade somatória, horizontal e cartesiana, predomina, mesmo que bidirecional; nos quadros, a organização caótica promove ambiguidades, tessitura relacional. 
Essas imagens inspiram "ao mesmo tempo clima e linguagem" (Staiger, 1972, p. 28). Inspiram porque, conforme esperamos ter demonstrado, a emotividade exuberante dá o tom. E a impregnação em absolutamente todos os lugares da capital paulista cria um "clima", ou, em linguagem teórica, realidades líricas, modelos de sensibilidade de semântica extremada.

Negar que nesses textos visuais confluem estilos significa contrariar a realidade empírica. O ponto de vista divisionista desconsidera raízes indiscutíveis da constituição cultural híbrida brasileira, muito ao gosto do sectarismo autoritário que predomina no país - não à toa, João Dória, ex-prefeito de São Paulo, atual governador e provável candidato à presidência, empreendeu uma guerra aos pichadores da capital em 2017, enquanto exaltava os grafiteiros, ou "muralistas", conforme ele preferia distinguir.

\section{REFERÊNCIAS}

Aguilar, G. (2005). Poesia concreta Brasileira: as vanguardas na encruzilhada modernista. São Paulo: Edusp.

Aristóteles. (1991). Poética. Tradução, comentários e índices analítico e onomástico de Eudoro de Souza. Seleção de textos de José Américo Motta Pessanha. São Paulo: Nova Cultural.

Art, L., Neelon, C. \& Manco, T. (2005). Graffiti Brasil. Londres: Thames \& Hudson.

Baudrillard, J. (1996). Kool Killer ou a Insurreição pelos signos. In J. Baudrillard, A troca simbólica e a morte (pp. 99-111). São Paulo: Loyola.

Boleta (2006). Ttsss... A grande arte da pixação em São Paulo. São Paulo: Editora do Bispo.

Bremond, C. (2008). A lógica dos possíveis narrativos. In R. Barthes et al. (Eds.), Análise estrutural da narrativa (pp. 114-141). Petrópolis: Vozes.

Brik, O. (1976). Ritmo e sintaxe. In B. Eikhenbaum et al. (Eds.), Teoria da literatura: formalistas russos (pp. 131139). Porto Alegre: Editora Globo.

Campos, H. de (1975). Evolução de formas: poesia concreta. In A. de Campos, D. Pignatari \& H. de Campos (Eds.), Teoria da poesia concreta (pp. 49-58). São Paulo: Duas Cidades.

Casseano, P., Domenich, M. \& Rocha, J. (2001). Hip Hop, a periferia grita. São Paulo: Editora Fundação Perseu Abramo.

Chastanet, F. (2007). Pixação: São Paulo signature. Toulouse: XGpress.

Chklovski, V. (1976). A arte como procedimento. In B. Eikhenbaum et al. (Eds.), Teoria da literatura: formalistas russos (pp. 39-56). Porto Alegre: Globo.

Descartes, R. (2001). Discurso do método. São Paulo: Martins Fontes.

Ferreira, L. T. (2006). O traçado das redes: etnografia dos grafiteiros e a sociabilidade na metrópole. Dissertação de Mestrado, Universidade Federal de São Carlos, São Carlos, Brasil.

Fideles, N. (Ed.) (2014). O movimento hip hop no Brasil. São Paulo: Editora Caros Amigos.

Fonseca, C. (1981). A poesia do acaso (na transversal da cidade). São Paulo: T. A. Queiroz Editor. 
Franco, S. M. (2009). Iconografias da metrópole: grafiteiros e pichadores representando o contemporâneo.

Dissertação de Mestrado, Universidade de São Paulo (USP), São Paulo, Brasil.

Frye, N. (1973). Anatomia da crítica. São Paulo: Cultrix.

Ganz, N. (2010). O mundo do grafite: arte urbana dos cinco continentes. São Paulo: Livraria Martins Fontes.

Gitahy, C. (1999). O que é graffiti. São Paulo: Brasiliense.

Hegel, G. W. F. (2004). Cursos de estética IV. São Paulo: Edusp.

Ivanov, V. V., Toporóv, V.N. \& Zalizniak, A. A. (1979). Sobre a possibilidade de um estudo tipológico-estrutural de alguns sistemas semióticos modelizantes. In B. Schnaiderman (Ed.), Semiótica Russa (pp. 81-96). São Paulo: Perspectiva.

Jakobson, R. (1983). O dominante. In L. C. Lima (Ed.), Teoria da literatura em suas fontes (pp. 485-491). Rio de Janeiro: Francisco Alves.

Jakobson, R. (2007). Linguística e poética. In R. Jakobson, Linguística e comunicação (pp. 118-162). São Paulo: Cultrix.

Lassala, G. (2010). Pichação não é pixação: uma introdução à análise de expressões gráficas urbanas. São Paulo: Altamira Editorial.

Leite, L. C. M. (2005). O foco narrativo (ou a polêmica em torno da ilusão). São Paulo: Ática.

Leminski, P. (2001). Anseios crípticos 2. Curitiba: Criar Edições.

Lotman, I. (1978). A estrutura do texto artístico. Lisboa: Editorial Estampa.

Malland, J. S. (2012). Tropical spray. São Paulo: Martins Fontes.

Morin, E. (2013). O método 1: a natureza da natureza. Porto Alegre: Sulina.

Morin, E. (2008). Introdução ao pensamento complexo. Lisboa: Instituto Piaget.

Pignatari, D. (1975). Poesia concreta: pequena marcação histórico-formal. In A. de Campos, H. de Campos \& D. Pignatari (Eds.), Teoria da poesia concreta (pp. 62-70). São Paulo: Livraria Duas Cidades.

Pound, E. (1990). ABC da literatura. São Paulo: Cultrix.

Richter, H. (1973). Historia del dadaísmo. Buenos Aires: Ediciones Nueva Visión.

Silva, A. (2014). Atmosferas urbanas: grafite, arte pública, nichos estéticos. São Paulo: Edições SESC São Paulo.

Silver, T. (Realizador). (1983). Style Wars [Documentário]. Estados Unidos da América: Public Art Productions.

Staiger, E. (1972). Conceitos fundamentais de poética. Rio de Janeiro: Tempo Brasileiro.

Todorov, T. (1969). As estruturas narrativas. São Paulo: Perspectiva.

Todorov, T. (1971). Estruturalismo e poética. São Paulo: Perspectiva.

Todorov, T. (1980). Os gêneros do discurso. São Paulo: Martins Fontes. 


\section{NOTA BIOGRÁFICA}

Marcos Zibordi é doutor em Ciências da Comunicação, professor substituto do curso de Jornalismo da Universidade de São Paulo (USP). Integrante do grupo de pesquisa Epistemologia do Diálogo Social (ECA-USP). Como jornalista, atua na crítica de conteúdo do portal UOL.

ORCID: http://orcid.org/oooo-0003-4818-2117

Email: mzibordi@hotmail.com

Morada: Escola de Comunicações e Artes (ECA), Campus central, Universidade de São Paulo (USP), Brasil

Submissão: 25/08/2019

Aceitação: 24/11/2019 